\title{
Uncertainties in reactive uptake coefficients for solid stratospheric particles-2. Effect on ozone depletion
}

\author{
Kenneth S. Carslaw and Thomas Peter \\ Max Planck Institute for Chemistry, Mainz, Germany \\ Rolf Müller \\ Institute for Stratospheric Chemistry, Forschungszentrum Jülich, Jülich, Germany
}

\begin{abstract}
Uncertainties in reactive uptake coefficients for reactions involving $\mathrm{HCl}, \mathrm{ClONO}_{2}$ and $\mathrm{HOCl}$ on nitric acid trihydrate (NAT) and sulfuric acid tetrahydrate (SAT) are shown to affect modeled Arctic stratospheric ozone depletion in a photochemical box model. The main contribution to the difference arises from the reaction $\mathrm{ClONO}_{2}+\mathrm{HCl} \rightarrow \mathrm{Cl}_{2}+$ $\mathrm{HNO}_{3}$ in early to mid-winter. During this period, differences in predicted $\mathrm{HCl}$ and $\mathrm{ClONO}_{2}$ are more than $1 \mathrm{ppbv}$ for several weeks when an upper limit for solid PSC existence is assumed. Ozone depletion is greater when liquid aerosols persist through the winter compared with cases where solid particles are assumed to form.
\end{abstract}

\section{Introduction}

The most important heterogeneous reactions leading to activation of chlorine reservoir gases in the polar stratosphere are

$$
\begin{aligned}
\mathrm{ClONO}_{2}+\mathrm{HCl} & \rightarrow \mathrm{Cl}_{2}+\mathrm{HNO}_{3}, \\
\mathrm{ClONO}_{2}+\mathrm{H}_{2} \mathrm{O} & \rightarrow \mathrm{HOCl}+\mathrm{HNO}_{3}, \\
\mathrm{HOCl}+\mathrm{HCl} & \rightarrow \mathrm{Cl}_{2}+\mathrm{H}_{2} \mathrm{O} .
\end{aligned}
$$

In companion paper I it was shown that various laboratory measurements for these key reactions on frozen stratospheric aerosol materials (NAT and SAT) could differ considerably when extrapolated to typical stratospheric conditions. Here, we investigate the potential effect of these uncertainties on modeled chlorine activation and ozone destruction in a photochemical box model for typical Arctic conditions.

\section{Uptake Rates Under Stratospheric Conditions}

Two different schemes for reactions R1-3 on solid particles are considered, see Table 1 . Scheme 1 is considered to be an upper limit of the reactive uptake coefficients, and is based on the measurements of Hanson and Ravishankara [1993]. Scheme 2, a lower limit, is derived from the measurements of Abbatt and Molina [1992a,b] on NAT and Zhang et al. [1994] on SAT, as described in paper I.

Figure 1 shows calculated uptake coefficients under stratospheric conditions, as well as the approximate reaction lifetime of $\mathrm{ClONO}_{2}$ or $\mathrm{HOCl}(\tau)$ for a particle surface area of 10

Copyright 1997 by the American Geophysical Union.

Paper number 97GL01684.

0094-8534/97/97GL-01684\$05.00 $\mu \mathrm{m}^{2} \mathrm{~cm}^{-3}$. For reaction R1 on NAT, the two schemes are in reasonable agreement at the ice frost point $(2 \mathrm{hrs}<\tau<7$ hrs), but differ substantially just below the NAT formation temperature ( 1 day $<\tau<3$ months). It is therefore under marginal PSC conditions close to the NAT equilibrium temperature that uncertainties in reaction rates will be most important for calculations of chlorine activation.

The rate of reaction $\mathrm{ClONO}_{2}+\mathrm{H}_{2} \mathrm{O}$ on NAT and SAT is also uncertain. Henson et al. [1996] have shown that the variation of $\gamma_{\mathrm{ClONO}_{2}}$ with water partial pressure and temperature can be well described in terms of the humidity. They restricted their analysis to the data of Abbatt and Molina [1992a] for NAT and Zhang et al. [1994] for SAT. However, as shown in Fig. 1, the measured uptake coefficients of Hanson and Ravishankara [1993] for NAT are systematically higher, by as much as a factor of 6-7 at the NAT equilibrium temperature. We take the Hanson and Ravishankara [1993] measurements as an upper limit of $\gamma_{\mathrm{ClONO}_{2}}$ (scheme 1), and those of Abbatt and Molina [1992a] as a lower limit (scheme 2). The measurements of Zhang et al. [1994] and Hanson and Ravishankara [1993] for this reaction are in reasonable agreement for SAT.

\section{The Photochemical Box-Model}

The Mainz photochemical box model is described by Müller et al. [1994]. A comprehensive set of chemical reactions is integrated using the Gear-code method FACSIMILE [Curtis and Sweetenham, 1987], and photolysis rates are calculated by the method of Lary and Pyle [1991]. Here, we describe only the updated aspects of the model that are important to the present work.

The model includes ternary $\mathrm{HNO}_{3}-\mathrm{H}_{2} \mathrm{SO}_{4}-\mathrm{H}_{2} \mathrm{O}$ liquid aerosols with an equilibrium composition calculated according to Carslaw et al. [1995]. The solubility of $\mathrm{HOCl}$ is calculated according to Huthwelker et al. [1995] and that of $\mathrm{HCl}$ from Luo et al. [1995]. Reactions R1-3 are included for the liquid aerosols, with rates calculated using expressions given by Hanson and Ravishankara [1994] and Hanson et al. [1994]. The reaction $\mathrm{N}_{2} \mathrm{O}_{5}+\mathrm{H}_{2} \mathrm{O}$ is included with $\gamma=0.1$.

Particle phase transitions. Transitions between liquid, NAT, SAT and ice particles are complex, and still not fully understood [Peter, 1997]. Most important to this work, it remains uncertain what proportion of stratospheric aerosols are solid or liquid at any one time. To examine the effect of different solid phase reaction schemes, we adopt the scenario for solid particle formation shown in Fig. 2, assuming that $\mathrm{HNO}_{3}-\mathrm{H}_{2} \mathrm{SO}_{4}-\mathrm{H}_{2} \mathrm{O}$ droplets freeze completely (to form NAT and SAT) at the NAT equilibrium temperature. We note 
Table 1. Heterogeneous parameters used in photochemical box model simulations.

\begin{tabular}{|c|c|c|}
\hline Reaction & scheme 1 & scheme 2 \\
\hline \multirow[t]{2}{*}{$\mathrm{ClONO}_{2}+\mathrm{HC}^{(2)}$} & $\begin{array}{l}\text { on NAT: } \\
\gamma_{0}=0.7022 \exp \left[-0.518\left(T-T_{\text {ice }}\right)\right] \\
1 / \gamma=1 / 0.23+1 /\left[\gamma_{0} \times\left(p_{\text {HCl }} / 7.5 \times 10^{-8} \text { torr }\right)^{0.6}\right] \\
\text { on SAT: }\end{array}$ & $\begin{array}{l}1 / \gamma=1 / \alpha+1 / A \theta_{\mathrm{HCl}} \\
\theta_{\mathrm{HCl}}=K_{\mathrm{HCl}} p_{\mathrm{HCl}} \\
\text { on NAT: } K_{\mathrm{HCl}}=\exp \left(-1.8+8.7 s_{\mathrm{ice}}\right) \mathrm{Pa}^{-1} \\
\quad A=8.2, \alpha=0.3\end{array}$ \\
\hline & $\begin{array}{l}1 / \gamma=1 / 0.23+1 / \exp \left[-0.636-0.4802\left(T-T_{\text {ice }}\right)\right][\text { note b] } \\
T_{\text {ice }}=\text { ice frost point } \\
\text { Hanson and Ravishankara }[1993]\end{array}$ & $\begin{array}{l}\text { on SAT: } K_{\mathrm{HCl}}=\exp \left(0.59+7.3 s_{\mathrm{ice}}^{1 / 2}\right) \mathrm{Pa}^{-1} \\
\quad A=1.1, \alpha=0.1 \\
\text { Eqns. from companion paper I }\end{array}$ \\
\hline $\mathrm{HOCl}+\mathrm{HCl}^{(\mathrm{c})}$ & as in scheme 2 & $\begin{array}{l}1 / \gamma=1 / \alpha+1 / A \theta_{\mathrm{HCl}} \\
\text { on NAT: } A=5.1, \alpha=0.15\end{array}$ \\
\hline $\mathrm{CONO}_{2}+\mathrm{H}_{2} \mathrm{O}$ & $\begin{array}{l}\text { on NAT: } \gamma=\exp \left(-9.03+2.81 s_{\text {ice }}\right) \\
\text { Hanson and Ravishankara }[1993] \\
\text { on SAT: } \gamma \text { as in scheme } 2\end{array}$ & $\begin{array}{l}\text { on NAT: } \gamma=\exp \left(-11.47+4.97 s_{\mathrm{ice}}\right) \\
\text { on SAT: } \gamma=\exp \left(-7.41+2.94 s_{\mathrm{ice}}\right) \\
\text { see note } \mathrm{d}\end{array}$ \\
\hline
\end{tabular}

\footnotetext{
Other uptake coefficients in the box model were taken from DeMore et al. [1994].

a In scheme 2, R1 is assumed to depend linearly on the HCl partial pressure, as described in paper I. In scheme 1 we use Hanson and Ravishankara's parameterized uptake coefficient expression appropriate for 1-2 ppbv at 50 torr (their Eqs. 1 and 3 ) and assume a weak variation with $\mathrm{HCl}$ partial pressure of $\gamma \propto p_{\mathrm{HCl}}^{0.6}$, as suggested by their additional measurements for a range of $p_{\mathrm{HCl}}$

b To prevent $\gamma>1$ a limit of 0.23 was used for $\gamma_{\mathrm{ClONO}}$ on SAT, as recommended by Hanson and Ravishankara [1993] for NAT.

'The fitted data of Abbatt and Molina [1992b] were used in both schemes (see companion paper I).

dFunctions were fitted to data of Abbatt and Molina [1992a] for NAT and Zhang et al. [1994] for SAT.
}

that the scenario in Fig. 2 likely produces close to an upper limit for the frequency with which solid particles occur. Using this upper limit for solid particle existence, combined with upper and lower limits for reaction rates on the solid particles, allows the maximum likely uncertainties (for example, in ozone depletion) due to solid phase kinetics to be examined. A further uncertainty in trying to calculate chlorine activation and ozone loss is, of course, how often solid particles actually exist. This may be important since, as shown

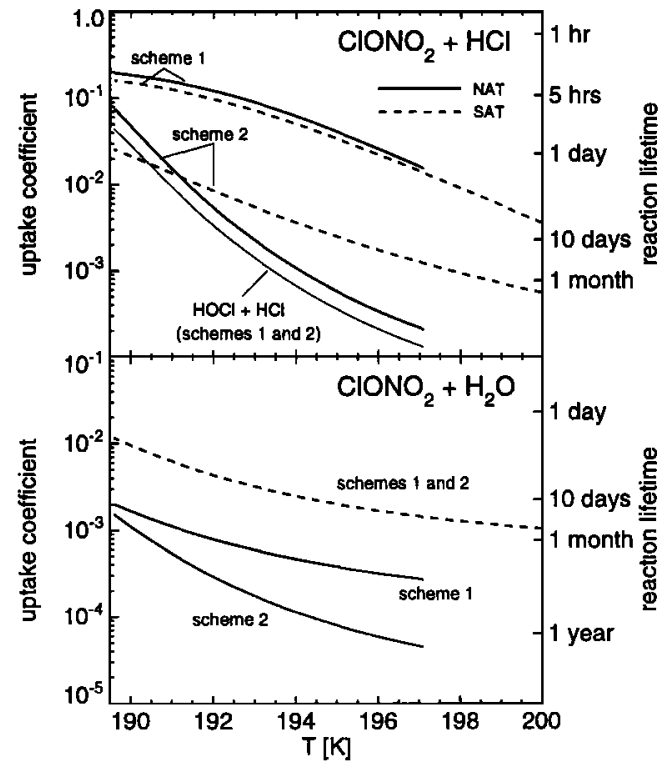

Figure 1. Reactive uptake coefficients under stratospheric conditions ( $60 \mathrm{mb}$ pressure, 5 ppmv $\mathrm{H}_{2} \mathrm{O}, 2$ ppv $\mathrm{HCl}$ ). Solid lines - reactions on NAT; dashed lines - reactions on SAT. Uptake coefficient expressions are given in Table 1. Reaction lifetime $\tau=4 / \bar{v} A$, where $\bar{v}$ is the mean molecular speed of $\mathrm{ClONO}_{2}$ and $A$ is the particle surface area density $\left(10 \mu \mathrm{m}^{2}\right.$ $\mathrm{cm}^{-3}$ ). Uptake coefficients for NAT are given only below the NAT equilibrium temperature with $10 \mathrm{ppbv} \mathrm{HNO}_{3}$. The lower temperature in the figure is the ice frost point. by Ravishankara and Hanson [1996], reaction rates on solid and liquid particles can be different. The effect of liquid versus solid heterogeneous processing is explored below.

Trajectory and Initialisation. The long-term trajectory (1 December - 15 April) of a typical air parcel confined within the Arctic vortex was simulated for the winter 1994/95 by imposing a latitude oscillation from 58 to $78^{\circ} \mathrm{N}$ as well as a temperature oscillation of $\pm 10 \mathrm{~K}$ amplitude, with maximum and minimum temperatures adjusted to agree with ECMWF polar vortex analyses. Further, the air parcel was assumed to descend from a potential temperature of 625 $\mathrm{K}$ in late November to $425 \mathrm{~K}$ in late March, as derived from HALOE methane measurements for the 1994/95 winter. Such simulated trajectories [Müller et al., 1994; Brühl et al., 1996] serve as a useful test-bed for comparison between different chemical schemes within the well-defined conditions of the vortex, although do not allow the motion of a real air parcel to be followed.

Mixing ratios of $\mathrm{O}_{3}(3.6 \mathrm{ppmv}), \mathrm{H}_{2} \mathrm{O}(5.4 \mathrm{ppmv}), \mathrm{HCl}$ (1.77 ppbv), NO, $\mathrm{NO}_{2}$ and $\mathrm{CH}_{4}$ were initialised using observations from HALOE inside the vortex on 1 December 1994. Total inorganic chlorine $\mathrm{ClX}(3.14 \mathrm{ppbv})$ was initialised from $\mathrm{HALOE} \mathrm{HF}$ and a $\mathrm{ClX}-\mathrm{HF}$ correlation with

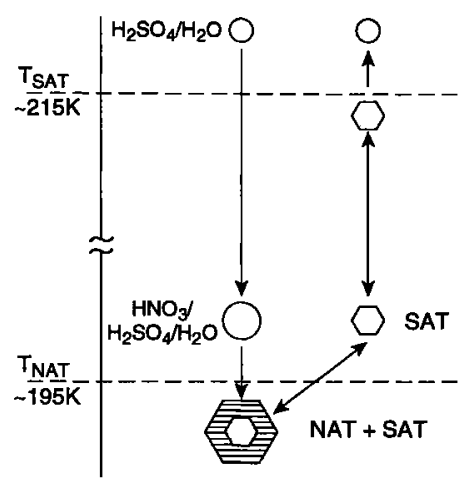

Figure 2. Particle phase transitions used in the box model simulations. 
latitude and season-dependent coefficients obtained from results of the Mainz two-dimensional chemistry model (Grooß, 1996). Initial partitioning between $\mathrm{HCl}, \mathrm{ClONO}_{2}(1.19$ ppbv), $\mathrm{HOCl}$ and $\mathrm{ClO}$ was also determined from the Mainz 2-D model, as well as NOy (14.1 ppbv) from the model NOy - HF correlation. The amount of sulfuric acid aerosol at the beginning of the trajectory was adjusted to agree with aerosol surface areas derived from HALOE extinction measurements and amounted to $0.4 \mathrm{ppbv} \mathrm{H}_{2} \mathrm{SO}_{4}$ in the air parcel.

\section{Results}

Figure 3 shows the air parcel temperature (a), NAT, SAT and liquid surface areas (b), mixing ratios of $\mathrm{ClONO}_{2}$ and $\mathrm{HCl}$ (c), $\mathrm{ClO}+2 \times \mathrm{Cl}_{2} \mathrm{O}_{2}$ (d), ozone loss rate (e), and ozone mixing ratio (f).

The differences between reactive uptake coefficients in the two schemes lead to significant differences in the amount of activated chlorine (d) and hence in the rate of ozone loss

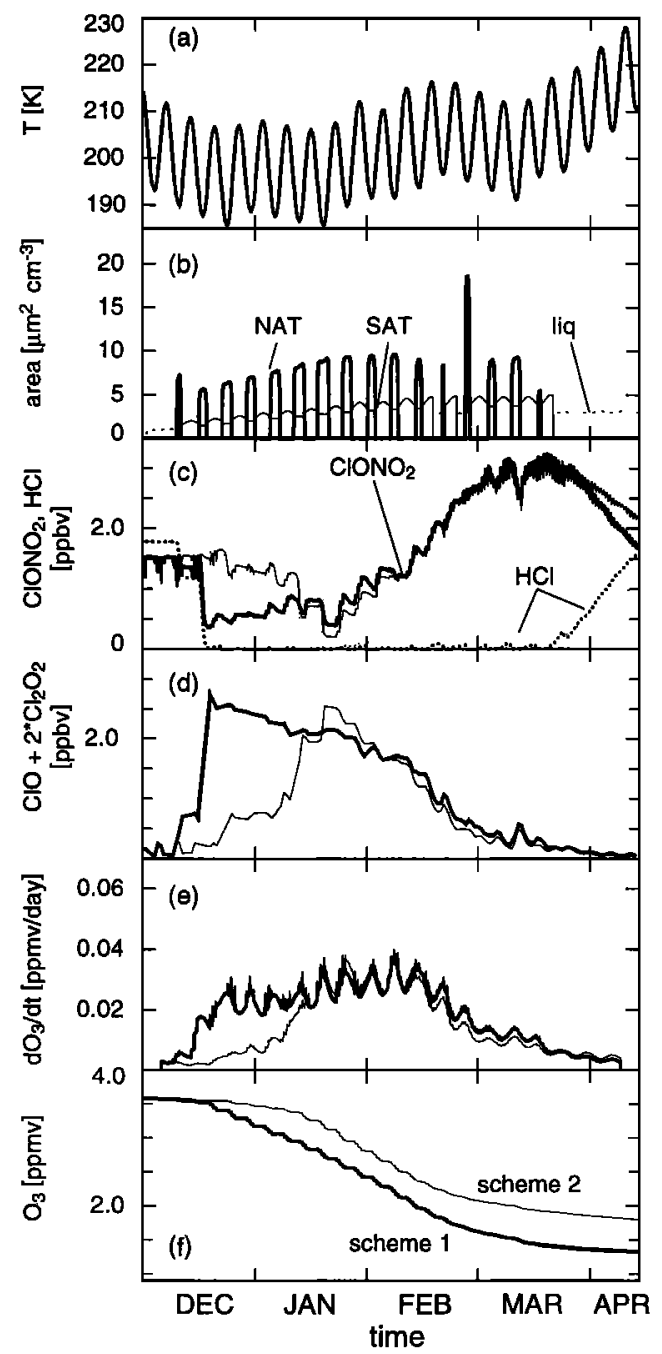

Figure 3. Box model results for the Arctic winter 1994/95 assuming particle phase transitions in Fig. 2. Thin lines using scheme 2 in Table 1 ; thick lines - scheme 1 . In (d) $2 \times \mathrm{Cl}_{2} \mathrm{O}_{2}+\mathrm{ClO}$ are noontime values. Ozone depletion rates are 5 day means. Particle surface areas are approximately the same in both cases. (e), particularly in December and early January. The greatest contribution to the difference is due to the reaction $\mathrm{ClONO}_{2}$ $+\mathrm{HCl}$; complete $\mathrm{HCl}$ depletion is predicted to occur by midDecember using scheme 1 , but only by late January using scheme 2. The ozone destruction rate during this period is up to a factor 4 higher with scheme 1 . The calculated ozone loss by the end of the winter is 2.3 ppmv (corresponding to $64 \%$ ) with scheme 1 , compared with only 1.8 ppmv (50\%) with scheme 2. Henson et al. [1996] present an alternative formulation for reaction R1, yielding uptake coefficients of up to a factor 40 lower than Hanson and Ravishankara [1993]. Replacing these in our scheme 2 yields ozone loss of 2.1 ppmv, midway between our schemes 1 and 2 .

The reaction $\mathrm{ClONO}_{2}+\mathrm{H}_{2} \mathrm{O}(\mathrm{R} 2)$ on solid particles is much less important as a source of active chlorine than the reaction with $\mathrm{HCl}$; even with a NAT surface area of $10 \mu \mathrm{m}^{2}$ $\mathrm{cm}^{-3}$ the reaction lifetime of $\mathrm{ClONO}_{2}$ is on the order of 10 days close to the ice frost point (Fig. 1). Furthermore, the greatest difference in $\gamma_{\mathrm{ClONO}_{2}}$ between schemes 1 and 2 occurs close to the NAT equilibrium temperature, where the reaction lifetime is longer than a month. Differences between the two schemes regarding reaction $\mathrm{R} 3$ are therefore unimportant.

We have made similar comparisons for the winters $1992 / 3$, 1993/4 and 1995/6, and find, as in Fig. 3, that the ozone destruction rates differ significantly only while $\mathrm{HCl}$ concentrations remain high, which is typically until mid- to late January. The greatest difference is predicted to occur during the winter 1993/4, which was comparably warm [Naujokat et al., 1994], leading to sporadic and infrequent NAT formation and $\mathrm{O}_{3}$ destruction rates in January up to 5 times higher using scheme 1 compared with scheme 2 . This large effect can be explained by the large differences in reactivity when temperatures are close to the NAT formation temperature (Fig. 1).

\section{Role of Liquid Aerosols}

Sensitivity calculations were also performed assuming that only liquid aerosols existed throughout the winter (results not shown). All the reactions R1-3 are faster on liquids than on NAT and SAT [Ravishankara and Hanson, 1996]. For the winter 1994/95 shown in Fig. 3, ozone loss was calculated to be almost identical to the results using scheme 1 (thick lines) until mid-March. This is because the higher uptake coefficient for reaction R1 on liquids [Ravishankara and Hanson, 1996] is compensated by the shorter duration of large liquid surface areas when compared with NAT in equilibrium. In mid-March, the brief cold period led to rapid conversion of $\mathrm{ClONO}_{2}$ to $\mathrm{HOCl}$ with liquid aerosols, due to the approximate factor 10 higher uptake coefficient for reaction R2 compared with NAT [Ravishankara and Hanson, 1996]. This led to a further $0.3 \mathrm{ppmv}$ ozone loss beyond that calculated using scheme 1 in Fig. 3.

Further sensitivity model runs were made assuming that NAT forms only $3 \mathrm{~K}$ below the NAT equilibrium temperature. This substantially reduces the frequency with which NAT occurs, but leaves the frequency of SAT occurrence almost unchanged. This led to 2.1 ppmv $\mathrm{O}_{3}$ loss with scheme 1 and 1.7 ppmv with scheme 2 , which is less than the depletion in Fig. 3 mainly because of the lower particle surface areas that result from suppressing NAT formation. A fourth case in which NAT formed at the NAT equilibrium tempera- 
ture, but upon evaporation released liquid aerosols instead of SAT, led to 2.5 ppmv loss with scheme 1 (very close to that predicted assuming liquid aerosols only) and 2.3 ppmv using scheme 2 . These preliminary comparisons indicate that the presence of liquid aerosols can enhance ozone depletion rates beyond those calculated assuming that solid particles predominate (using either scheme 1 or 2). More thorough investigations are required to fully understand these differences.

\section{Discussion}

It is commonly assumed that the occurrence of NAT PSCs leads to the rapid heterogeneous conversion of $\mathrm{ClONO}_{2}$ and $\mathrm{HCl}$ to $\mathrm{Cl}_{2}$ within a period that is short compared to the overall process of ozone destruction. We have shown here that existing laboratory measurements for this reaction are consistent with a lifetime of these species of between about 3 months and a few hours for temperatures between the NAT equilibrium temperature and the ice frost point. Because the predicted uptake coefficients cannot always be considered fast on the timescale of ozone destruction, the large uncertainties that exist in their measurement do strongly affect the extent of ozone depletion on the timescale of an Arctic winter.

Model simulations using the minimum likely uptake coefficients on solid particles (scheme 2 in Table 1 ) predict ozone destruction that is less than estimated from HALOE observations in the winter 1994/95 Arctic vortex (1.8 ppmv compared with 2.5 ppmv [Brühl et al., 1996]). A reliable comparison with observations is difficult due to the idealised nature of the trajectory that was used, and the significance of this difference should be interpreted with caution. However, it is worth noting from this preliminary study that the significantly lower reactive uptake coefficients used in scheme 2 cannot be excluded.

These simulations probably represent an upper limit to the difference in model-calculated ozone loss due to uncertainties in solid particle heterogeneous reaction rates. The results suggest that care should be taken when comparing with observations, either with long-term simulations, but particularly with individual case studies. These uncertainties in $\mathrm{O}_{3}$ depletion must be compared with those arising from uncertainties in the phase of PSCs [Ravishankara and Hanson, 1996], which could be of the same order. Heterogeneous processing rates on liquids are generally faster than on solids, and the long-term simulations shown here suggest that one consequence of solid PSC formation may be to reduce chlorine activation and ozone depletion.

A key indicator of which scheme is operating in the stratosphere is the amount of $\mathrm{HCl}$ in early winter. Simultaneous observations of $\mathrm{HCl}$ and measurements of aerosol phase along air-parcel trajectories would help to better define the role of PSC phase in ozone depletion.

Acknowledgments. We are grateful to Christoph Brühl for preparing the trajectory and chemical initialisation, and David Lary for providing the photolysis program. Partly funded by the European Community under contract ENV4-CT95-0050 and the German BMBF under contract 01 LO 9506/0.

\section{References}

Abbatt, J. P. D. and M. J. Molina, Heterogeneous interactions of
$\mathrm{ClONO}_{2}$ and $\mathrm{HCl}$ on nitric acid trihydrate at $202 \mathrm{~K}, J$. Phys. Chem., 96, 7674-7679, 1992a.

Abbatt, J.P.D. and M.J. Molina, The heterogeneous reactions of $\mathrm{HOCl}+\mathrm{HCl} \rightarrow \mathrm{Cl}_{2}+\mathrm{H}_{2} \mathrm{O}$ on ice and nitric acid trihydrate: Reaction probabilities and stratospheric implications, Geophys. Res. Lett., 19, 461-464, 1992 b.

Brühl, Ch., K.S. Carslaw, J. Russell, Chemical ozone depletion in Arctic winter 94/95: HALOE observations and box model calculations, in Polar Stratospheric Ozone, Proceedings of the 3rd European Workshop, J.A. Pyle et al. (Eds.), European Commission, 609-614, 1996.

Carslaw, K.S., B.P. Luo, Th. Peter, An analytic expression for the composition of aqueous $\mathrm{HNO}_{3}-\mathrm{H}_{2} \mathrm{SO}_{4}-\mathrm{H}_{2} \mathrm{O}$ stratospheric aerosols including gas phase removal of $\mathrm{HNO}_{3}$, Geophys. Res. Lett., 22, 1877-1880, 1995.

Curtis, A.R. and W.P. Sweetenham, Facsimile/Checkmat Users Manual, Computer Science and Systems Division, Harwell Laboratory, Oxford, 135 pp., 1987.

DeMore et al. Chemical Kinetics and Photochemical Data for Use in Stratospheric Modeling, JPL Publication 94-26, 1994.

GrooB, J.-U., Modelling of Stratospheric Ozone based on HALOEUARS Satellite Data, PhD thesis, 135 pp, Mainz, Shaker Verlag, Aachen, 1996.

Hanson, D.R. and A.R. Ravishankara, Investigation of the reactive and nonreactive processes involving $\mathrm{ClONO}_{2}$ and $\mathrm{HCl}$ on water and nitric acid doped ice, J. Phys. Chem., 96, 2682-2691, 1992.

Hanson, D.R. and A.R. Ravishankara, Reaction of $\mathrm{ClONO}_{2}$ with $\mathrm{HCl}$ on NAT, NAD, and frozen sulfuric acid and hydrolysis of $\mathrm{N}_{2} \mathrm{O}_{5}$ and $\mathrm{ClONO}_{2}$ on frozen sulfuric acid,J. Geophys. Res., 98, 22,931-22,936, 1993.

Hanson, D.R. and A.R. Ravishankara, Reactive uptake of $\mathrm{ClONO}_{2}$ onto sulfuric acid due to reaction with $\mathrm{H}_{2} \mathrm{O}$ and $\mathrm{HCl}, J$. Phys. Chem., 98, 5728-5735, 1994.

Hanson, D.R., A.R. Ravishankara, S. Solomon, Heterogeneous reactions in sulfuric acid aerosols: A framework for model calculations, J. Geophys. Res., 99, 3615-3629, 1994.

Henson, B.F., K.R. Wilson, J.M. Robinson, A physical adsorption model of the dependence of $\mathrm{ClONO}_{2}$ heterogeneous reactions on relative humidity, Geophys. Res. Lett., 23, 1021-1024, 1996.

Huthwelker, T., et al., Solubility of $\mathrm{HOCl}$ in water and aqueous $\mathrm{H}_{2} \mathrm{SO}_{4}$ to stratospheric temperatures, J. Atmos. Chem., 21, 81 95, 1995.

Lary, D.J. and J.A. Pyle, Diffuse radiation, twilight and photochemistry, J. Atmos. Chem., 13, 373-406, 1991.

Luo, B.P., K.S. Carslaw, Th. Peter, S.L. Clegg, Vapour pressures of $\mathrm{H}_{2} \mathrm{SO}_{4}-\mathrm{HNO}_{3}-\mathrm{HCl}-\mathrm{HBr}-\mathrm{H}_{2} \mathrm{O}$ solutions to low stratospheric temperatures, Geophys. Res. Lett., 22, 247-250, 1995.

Müller, R., et al., Chlorine chemistry and the potential for ozone depletion in the Arctic stratosphere in the winter 1991/92, Geophys. Res. Lett., 21, 1427-1430, 1994.

Naujokat, B., et al., The stratospheric winter 1993/94: A winter with some minor warmings and an early final warming, Beil. Berlin. Wetterkarte, August 4, 1994.

Peter, Th., Microphysics and heterogeneous chemistry of polar stratospheric clouds, An. Revs. Phys. Chem., in press (1997).

Ravishankara, A.R. and D.R. Hanson, Differences in the reactivity of type I polar stratospheric clouds depending on their phase, $J$. Geophys. Res., 101, 3885-3890, 1996.

Zhang, R., J.T. Jayne and M.J. Molina, Heterogeneous interactions of $\mathrm{ClONO}_{2}$ and $\mathrm{HCl}$ with sulfuric acid tetrahydrate: Implications for the stratosphere, J. Phys. Chem., 98, 867-874, 1994.

K. S. Carslaw and Th. Peter, Max-Planck-Institut für Chemie, Postfach 3060, Mainz 55020, Germany. (e-mail: canslaw@mpchmainz.mpg.de; peter@nike.mpch-mainz.mpg.de)

R. Müller, Institut für Stratosphärische Chemie, Forschungszentrum Jülich, 52425 Jülich, Germany. (email: Ro.Mueller@fzjuelich.de

(Received October 22, 1996; revised February 27, 1997; accepted May 14, 1997.) 